\title{
Influence of High Energy Heavy Ions on Magnetic Susceptibility of Soft Magnetic Metallic Glasses
}

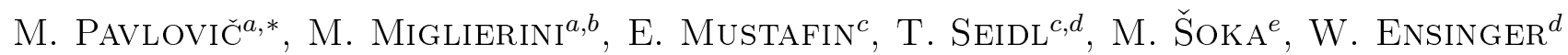 \\ ${ }^{a}$ Institute of Nuclear and Physical Engineering, Faculty of Electrical Engineering and Information Technology, \\ Slovak University of Technology, Ilkovičova 3, 81219 Bratislava, Slovakia \\ ${ }^{b}$ Regional Centre of Advanced Technologies and Materials, Palacky University, \\ 17. listopadu 12, 77146 Olomouc, Czech Republic \\ ${ }^{c}$ GSI Helmholtzzentrum für Schwerionenforschung GmbH, Planckstrasse 1, 64291 Darmstadt, Germany \\ ${ }^{d}$ Darmstadt University of Technology, Karolinenplatz 5, 64289 Darmstadt, Germany \\ ${ }^{e}$ Institute of Electrical Engineering, Faculty of Electrical Engineering and Information Technology, \\ Slovak University of Technology, Ilkovičova 3, 81219 Bratislava, Slovakia
}

\begin{abstract}
This contribution presents experimental data concerning the influence of fast heavy ions on magnetic susceptibility of VITROVAC ${ }^{\circledR} 6025$ and VITROPERM ${ }^{\circledR} 800$ metallic glasses. Samples of magnetic ribbons were irradiated with $\mathrm{Au}$, and $\mathrm{Ta}$ ions at $11.1 \mathrm{MeV} / \mathrm{A}$ (energy per nucleon), and $\mathrm{U}$ ions at $5.9 \mathrm{MeV} / \mathrm{A}$. The irradiation fluences varied from $5 \times 10^{10}$ up to $1.2 \times 10^{13}$ ions $/ \mathrm{cm}^{2}$. Relative change of the samples' magnetic susceptibility after and before irradiation was measured and evaluated as a function of the irradiation fluence. Measurements were done with a commercial Kappa-bridge device. We observed that VITROPERM ${ }^{\circledR}$ showed less change of magnetic susceptibility in comparison with VITROVAC ${ }^{\circledR}$ and this change occurred at higher fluences. This indicates higher radiation hardness of VITROPERM ${ }^{\circledR}$ compared with VITROVAC ${ }^{\circledR}$ against high-energy heavy ions. In addition, heavier ions caused larger change of magnetic susceptibility than the lighter ones and the effect could be roughly scaled with the level of electronic stopping.
\end{abstract}

DOI: $10.12693 /$ APhysPolA.126.54

PACS: $61.80 . \mathrm{Jh}, 61.82 . \mathrm{Bg}, 75.30 . \mathrm{Cr}, 75.47 . \mathrm{Np}, 75.50 . \mathrm{Kj}$

\section{Introduction}

Soft-magnetic metallic glasses are considered for magnetic cores of accelerator radio-frequency ( $\mathrm{RF}$ ) cavities. In this particular application, they are exposed to ion irradiation, which alters their magnetic properties. The radiation field is rather complex (different particles, energies and fluences) because it originates from interaction of lost primary heavy ions with the beam-pipe producing different secondary particles. That is why a systematic study of the influence of ion irradiation on magnetic properties of the soft-magnetic metallic glasses is important. Our study is connected to the FAIR project [1]. Having some experience with neutron- and laser-irradiation of different metallic glasses [2,3], we started with light ions $[4,5]$. However, the data for light ions cannot be extrapolated to heavy ions, because the mechanism of radiation damage is qualitatively different for light vs. heavy ions [6]. The recent work covers Ta, Au and $\mathrm{U}$ ions irradiating ribbons of VITROVAC ${ }^{\circledR} 6025$ and VITROPERM ${ }^{\circledR} 800$ [7] at energies of few $\mathrm{MeV} / \mathrm{A}$ (per nucleon). After irradiation, the samples showed changes of magnetic susceptibility. These changes were a function of irradiation fluence, ion mass as well as sample material.

*corresponding author; e-mail: marius.pavlovic@stuba.sk

\section{Materials and methods}

All irradiation experiments were performed at the UNILAC accelerator at GSI Helmholtzzentrum für Schwerionenforschung. The irradiation conditions are given in Table I.

A summary of irradiation conditions,

TABLE I

\begin{tabular}{c|c|c}
\hline \hline Material & $\begin{array}{c}\text { Ion, energy } \\
{[\mathrm{MeV} / \mathrm{A}]}\end{array}$ & Fluence [ions $\left./ \mathrm{cm}^{2}\right]$ \\
\hline VITROVAC $^{\circledR}$ & $\mathrm{Au}, 11.1$ & $\begin{array}{c}5 \times 10^{10}, 1 \times 10^{11}, 5 \times 10^{11} \\
1 \times 10^{12}, 3 \times 10^{12}\end{array}$ \\
\hline & $\mathrm{Ta}, 11.1$ & $\begin{array}{c}1 \times 10^{11}, 5 \times 10^{11}, 1 \times 10^{12} \\
2 \times 10^{12}, 5 \times 10^{12}, 1.2 \times 10^{13}\end{array}$ \\
\cline { 2 - 3 } VITROPERM $^{\circledR}$ & $\mathrm{Au}, 11.1$ & $\begin{array}{c}1 \times 10^{11}, 5 \times 10^{11}, 1 \times 10^{12} \\
2 \times 10^{12}, 5 \times 10^{12}\end{array}$ \\
\cline { 2 - 3 } & $\mathrm{U}, 5.9$ & $\begin{array}{c}1 \times 10^{11}, 5 \times 10^{11}, 1 \times 10^{12} \\
2 \times 10^{12}, 5 \times 10^{12}\end{array}$ \\
& &
\end{tabular}

Prior to each irradiation, simulations with SRIM2010 were run in the full-cascade mode in order to evaluate ionization density and radiation damage. Ionization density corresponds to electronic stopping. Radiation damage was converted to dpa (displacements pre atom) and corresponds to elastic nuclear scattering. Figure 1 shows ionization density and dpa for VITROPERM ${ }^{\circledR} 800$. Data for VITROVAC ${ }^{\circledR} 6025$ can be found in [8]. In all cases, the range of ions is longer than the sample thickness, that is about $23 \mu \mathrm{m}$. 
The samples were analysed by magnetic susceptibility measurements, using the commercial Kappa-bridge KLY-2 system [9]. Its operation is based on measurement of inductance-change of a pick-up coil due to presence of a magnetic specimen in its centre. The pick-up coil is a 6th-order compensated solenoid. The electric circuit is an accurate auto-balance inductivity bridge. The operating frequency is $920 \mathrm{~Hz}$. The absolute accuracy declared by the manufacturer is $\pm 3 \%$. Each set of samples contained one reference sample that was not irradiated and served for fine calibration. With this calibration, we estimate the accuracy of the presented data better than $\pm 1.5 \%$.

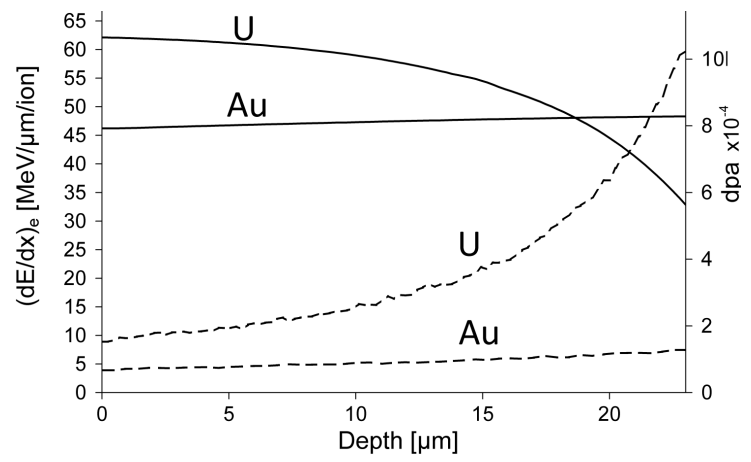

Fig. 1. Ionization density ( $\mathrm{dE} / \mathrm{dx}$, solid line, left scale) and radiation damage (dpa, dashed line, right scale) for $\mathrm{Au}$ and $\mathrm{U}$ ions in VITROPERM ${ }^{\circledR} 800$ simulated with SRIM2010 at irradiation fluence of $1 \times 10^{12}$ ions $/ \mathrm{cm}^{2}$.

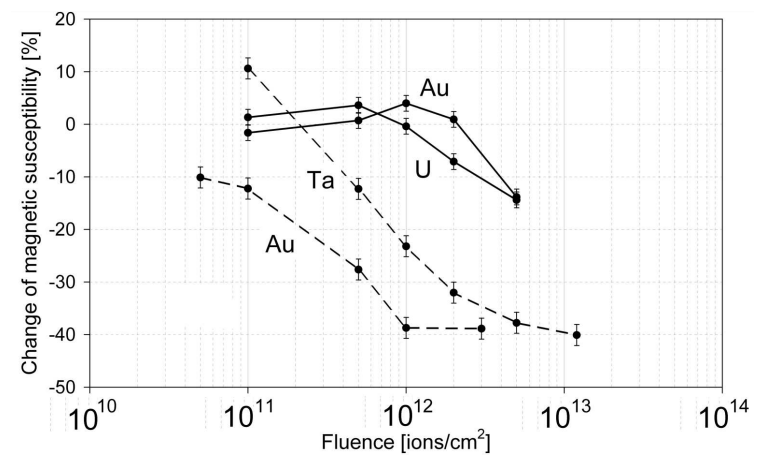

Fig. 2. Relative change of magnetic susceptibility induced by fast heavy ion irradiation as a function of irradiation fluence. VITROVAC ${ }^{\circledR} 6025$ - dashed line, VITROPERM ${ }^{\circledR} 800$ - solid line.

\section{Results, discussion and conclusions}

Figure 2 shows the measurement results in form of the relative change of magnetic susceptibility induced by ion irradiation as a function of irradiation fluence.

It is observed that: (1) the relative change of magnetic susceptibility is larger for VITROVAC ${ }^{\circledR} 6025$ in comparison with VITROPERM ${ }^{\circledR} 800$ and (2) the radiation damage caused by heavier ions is greater than the damage caused by lighter ions (see Tab. II for selected numerical data).

One can state as a conclusion that VITROPERM ${ }^{\circledR}$ type materials are radiation harder compared with VITROVAC ${ }^{\circledR}$-type materials against high energy heavy ion irradiation.

TABLE II

Relative change of magnetic susceptibility [\%].

\begin{tabular}{|c|c|c|c|c|}
\hline \multirow{2}{*}{$\begin{array}{c}\text { Fluence } \\
{\left[\text { ions } / \mathrm{cm}^{2}\right]}\end{array}$} & \multicolumn{2}{|c|}{ VITROVAC $^{\circledR}$} & \multicolumn{2}{|c|}{ VITROPERM $^{\circledR}$} \\
\hline & $\mathrm{Ta}$ & $\mathrm{Au}$ & $\mathrm{Au}$ & $\mathrm{U}$ \\
\hline $1 \times 10^{11}$ & 11 & -12 & -2 & 1 \\
\hline $5 \times 10^{11}$ & -12 & -28 & 1 & 4 \\
\hline $1 \times 10^{12}$ & -23 & -39 & 4 & 0 \\
\hline $2 \times 10^{12}$ & -32 & \multirow{2}{*}{$-39^{*}$} & 1 & -7 \\
\hline $5 \times 10^{12}$ & -38 & & -14 & -14 \\
\hline
\end{tabular}

\section{Acknowledgments}

This work was supported through the VEGA projects $1 / 0286 / 12$ and $1 / 1163 / 12$. Further support was provided by the Slovak Research and Development Agency (contract Nos. APVV-0062-11 and SK-PL-0032-12). Support from TU Darmstadt, BMBF 06DA90251, GSI Helmholtzzentrum für Schwerionenforschung $\mathrm{GmbH}$, CZ.1.07/2.3.00/20.0155, and CZ.1.05/2.1.00/03.0058 is acknowledged as well.

\section{References}

[1] P. Spiller, K. Blasche, B. Franczak, M. Kirk, P. Huelsmann, C. Omet, S. Ratschow, J. Stadlmann, Nucl. Instrum. Methods Phys. Res. Sect. A 544, 117 (2005).

[2] M. Miglierini, Mater. Sci. Eng. A 147, 101 (1991).

[3] M. Miglierini, P. Schaaf, I. Škorvánek, D. Janičkovič, E. Carpene, S. Wagner, J. Phys.: Condens. Matter 13, 10359 (2001).

[4] M. Miglierini, A. Lančok, M. Pavlovič, Hyperfine Interact. 189, 45 (2009).

[5] M. Miglierini, A. Lančok, M. Pavlovič, The Physics of Metals and Metallography 109, 469 (2010).

[6] A. Rivera, J. Olivares, G. García, J.M. Cabrera, F. Agulló-Rueda, F. Agulló-López, Phys. Status Solidi A 206, 1109 (2009).

[7] S. Flohrer, G. Herzer, J. Magn. Magn. Mater. 322, 1511 (2010).

[8] M. Pavlovič, M. Miglierini, E. Mustafin, T. Seidl, W. Ensinger, I. Strašík, M. Soka, Acta Phys. Pol. A 118(5), 754 (2010).

[9] V. Jančárik, E. Ušák, Journal of Electrical Engineering 50, 63 (1999). 